\title{
Editorial: The past, present, and future of Monthly Weather Review
}

DOI:

10.1175/2007MWR9047

Link to publication record in Manchester Research Explorer

\section{Citation for published version (APA):}

Schultz, D. M. (2008). Editorial: The past, present, and future of Monthly Weather Review. Monthly Weather Review, 136(1), 3-6. https://doi.org/10.1175/2007MWR9047

\section{Published in:}

Monthly Weather Review

\section{Citing this paper}

Please note that where the full-text provided on Manchester Research Explorer is the Author Accepted Manuscript or Proof version this may differ from the final Published version. If citing, it is advised that you check and use the publisher's definitive version.

\section{General rights}

Copyright and moral rights for the publications made accessible in the Research Explorer are retained by the authors and/or other copyright owners and it is a condition of accessing publications that users recognise and abide by the legal requirements associated with these rights.

\section{Takedown policy}

If you believe that this document breaches copyright please refer to the University of Manchester's Takedown Procedures [http://man.ac.uk/04Y6Bo] or contact uml.scholarlycommunications@manchester.ac.uk providing relevant details, so we can investigate your claim.

\section{OPEN ACCESS}




\section{EDITORIAL}

\section{The Past, Present, and Future of Monthly Weather Review}

Before the Internet, at a time when most publishing meteorologists recognized a PDF as a probability density function, submitting a manuscript to Monthly Weather Review $(M W R)$ required printing a file containing the text of the manuscript, creating each figure as a separate entity, pasting each figure into the manuscript, making five photocopies, writing a cover letter, and shipping the whole package of paper to the chief editor's office, often at a premium via overnight mail. All subsequent communication among the chief editor, the editor handling the contribution, the reviewers, and the corresponding author also required costly shipping of paper copies. Records of these transactions were kept in paper files in the editorial assistant's office. The result was that manuscript processing and time to decision took many months. Even as recently as a few years ago, accepted manuscripts were mailed to American Meteorological Society (AMS) headquarters and rekeyed by typists en route to being published.

Today, authors submit manuscripts to all AMS journals entirely in digital form and the complete peer-review and production process is conducted electronically. The Webbased Manuscript Tracking System also records metrics uniformly for all AMS journals, which helps editors stay abreast of and improve performance. Upon publication, manuscripts are stored and distributed to subscribers electronically. A bonus is that all AMS articles published five or more years ago from the present are freely available via open access to anyone online. More details of the publication process are described in Jorgensen et al. (2007).

Assisting the AMS to move forward with this all-electronic process have been the two co-chief editors of $M W R$, David Jorgensen and William (Bill) Skamarock, and the chief editorial assistant, Mary Golden. Under their leadership, $M W R$ has achieved the following:

1) Helping the AMS transition to an all-electronic implementation of manuscript submissions and reviews: $M W R$, its editors, and its editorial assistants have initiated and/or served as beta testers for many features of the Manuscript Tracking System and file storage server that have accelerated the AMS's ability to handle and process manuscripts. (The Journal of Climate also deserves acknowledgment for developing its own file storage server several years ago that in part inspired the AMS conversion.)

2) Leading AMS journals in time required for manuscripts to receive initial and final decisions: Speed to editorial decisions has been and remains a priority at $M W R$, spawning friendly competition among the editors. In 2006, $M W R$ had an average time to initial decision of 66 days and an average time to final decision of 161 days. These values are 22 and 17 days shorter than the second-place journals at the AMS and well below the journal-wide average of 92 and 206 days, respectively. $M W R$ is the only AMS journal that meets the standard set by the Publications Commission of an average time to initial decision of less than 10 weeks (Schubert 1999).

3) Overseeing growth from 250-300 submissions annually in 1997-2002 to 378 submissions in 2006: The majority of this increase is from the fields of data assimilation, ensemble forecast techniques and verification, and observational/modeling studies of mesoscale weather phenomena, fields in which many new techniques and observational platforms are being developed. This new volume of submitted manuscripts required the addition of an eighth $M W R$ editor in 2008 to avoid overtaxing editors and to maintain $M W R$ 's record of rapid processing. 


\section{Changes to the Editorial Board}

Unfortunately, both Dave and Bill are stepping down as co-chief editors this year, after 10 and $5 \mathrm{yr}$ of service, respectively. The new Editorial Board thanks them for their service to $M W R$ and the AMS. Both Dave and Bill will continue to serve the AMS Publications Commission: Dave as the new Publications Commissioner (replacing Joe Klemp) and Bill as the head of the Information Systems Committee.

Dave's and Bill's contributions could not have been as effective without the help of Mary Golden of Boulder, Colorado, who has served as the chief editorial assistant for $M W R$ for the last five years. Mary has been instrumental in accelerating the transition to an electronic workflow, training editors and editorial assistants, helping authors improve the quality of their writing, and reducing costs. She has also kept on top of reviews and revisions by reminding editors, reviewers, and authors of deadlines. The transition to all-electronic processing has enabled Mary to staff not two but seven editors. We are proud of Mary's accomplishments and look forward to her continuing contributions to $M W R$ and the AMS.

Editor Steve Cohn will step down this year after serving for four years. He has overseen a large increase in the number of submissions on data assimilation to $M W R$. Editorial Assistant Laura Rumburg has assisted Steve over the past four years.

I will become chief editor on 1 January 2008, after serving as an editor of $M W R$ for the past four years. My expertise is in synoptic-scale and mesoscale processes. Four new editors will join $M W R$ : Jeff Trapp of Purdue University, specializing in convective storms and radar meteorology; Jim Hansen of the Naval Research Laboratory in Monterey, California, with expertise in forecast verification; Fuqing Zhang of Texas A\&M University, with expertise in numerical techniques and data assimilation; and Tom Hamill of NOAA/ESRL, with expertise in ensemble forecast approaches. These scientists join present Editors Jim Doyle (mesoscale modeling expertise), Liz Ritchie (tropical meteorology and hurricane expertise), and Nolan Atkins (mesoscale convective systems expertise). Ida Buffone also continues as the highly skilled editorial assistant for Jim Doyle.

Thirty-three associate editors round out the Editorial Board. Associate editors help adjudicate conflicting reviews, identify reviewers, perform quality reviews in a timely manner, and provide general assistance and guidance to the editors.

This new $M W R$ Editorial Board is unique in a couple of ways. These eight editors make up one of the youngest boards ever for $M W R$, and this is the first time that $M W R$ has had a chief editor who is not affiliated with a U.S. institution. This new Editorial Board is dedicated to following the eight principles laid out in the "Author's Bill of Rights" editorial by Schubert (1999) and continuing MWR's history of publishing highquality research papers.

\section{The review process}

Certainly one of the most rewarding aspects of being an editor is overseeing the incredible amount of volunteer work that manuscript reviewers dedicate to peer review each year. Nearly a thousand $M W R$ reviews are performed annually by people who get no acknowledgment, credit, or pay for their hard work to improve the quality of submissions. Unfortunately, we can honor only one person a year per journal with an Editors' Award presented at the AMS Annual Meeting, but everyone deserves recognition.

A rule of thumb is that each person should review at least two or three times the number of papers he or she submits, although those with more experience need to contribute more than their share by the very nature of their expertise. With everyone's busy schedules, we editors are always grateful for the volunteerism that keeps the publication process moving forward.

Furthermore, we are pleased that so many authors take the comments provided by reviewers seriously. Although reading newly arrived reviews can be a shocking and emotional experience for authors, I think we all agree in hindsight that the exchange between reviewers, author, and editor improves nearly all submitted manuscripts.

Many people have used the $M W R$ Web page in the past. With the change in chief 
editor comes a new URL: http://www.ametsoc.org/pubs/journals/mwr/index.html. The new Web page will continue to provide instructions for authors and reviewers, publication statistics, and useful links. A new addition is the MWR Editors' Blog where the Editorial Board will discuss issues related to publishing and science: http://mwr-editors. blogspot.com. We will highlight articles published in the most recent issues of $M W R$, answer your questions about publishing and being editors, and present other items of general interest to $M W R$ readers. As always, we welcome feedback on this new concept.

\section{Encouraging submissions}

In addition to articles, $M W R$ publishes manuscripts in four other departments. Unique to $M W R$ are the departments Annual Summary and Picture of the Month; the departments Review and Notes and Correspondence also appear in other AMS journals. In fact, the $M W R$-specific departments are often the first that many subscribers go to upon receiving a new issue. $M W R$ previously published more submissions in these departments, but fewer are now received. The new Editorial Board encourages submissions in all of these categories, especially Review, Picture of the Month, and Correspondence.

Review might more properly be called literature synthesis. For students and scientists alike, many Reviews are as valuable as textbooks, albeit more current. Two examples include Keyser and Shapiro's (1986) Review on upper-level fronts and Schultz and Schumacher's (1999) Review on conditional symmetric instability. A common perception is that a Review is a quick publication, lacking new scholarship and merely summarizing previously published literature. This perception is inaccurate, for a good Review often requires more time and effort to research and write than does a regular research article. In a Review, the overarching theme should be clear. Boundaries of what will and will not be discussed should be stated explicitly early in the paper. Authors of Reviews should not be afraid to address the failures and limitations of research previously published, although fairness is imperative. Controversy is healthy in science, and all authors should dare to address these issues. In fact, the best Reviews can resolve outstanding controversies in the literature, especially if the agents of the controversy did not cleanly resolve them within their own published works. Furthermore, synthesizing the previous literature can be quite demanding as the author faces the scrutiny of all the previous authors cited-these cited authors depend on the review to explain and cite their literature accurately. The Editorial Board hopes to find new Reviews to publish in the upcoming years.

The Picture of the Month began in the early days of satellite imagery when $M W R$ was published by the National Weather Bureau. During the early 1970s, the Picture of the Month featured a satellite image with perhaps one or two supporting figures to demonstrate the capabilities of this emerging technology that would soon revolutionize weather forecasting. In today's scientific world, more than one lone image is usually needed as explanation, so a Picture of the Month necessarily has grown longer and more complicated. Simply submitting an image (now broadened to include photographic, radar, and other imagery) with some brief explanation generally does not suffice. Although speculation may be permissible if an explanation of an image is not forthcoming, a paper cannot stand on speculation alone.

As Errico (2000) reported, the number of "Comment and Reply" exchanges has decreased significantly over time. Since 2003, only seven "Comments on" papers have been published in $M W R$, compared to more than 1000 articles and notes. Editors know that some manuscripts are published without complete agreement between reviewers and authors, a situation that may be common with regard to new paradigms or controversial topics. The Editorial Board encourages those who have disagreements, amplifications, or additions to previously published literature in $M W R$ to submit their comments and engage in public discussion of these topics. Vigorous scientific exchange is a sign of an active discipline.

Finally, as Batchelor (1981) has stated, journals can select papers for publication only from among the manuscripts they receive as submissions. Editors may sometimes solicit papers directly from authors, but most papers arrive unannounced and unheralded. 
Occasionally, an author will approach us with a submission that is atypical of what we have published in the past, yet what we may wish to publish in the future. If you are writing such a paper, asking the chief editor in advance if he would accept such a submission can be useful. The importance of receiving submissions on the boundaries of the discipline or that are interdisciplinary cannot be overstated. If this did not occur, the scope of journals would shrink over time as the submissions would trend toward mainstream topics. To keep $M W R$ fresh and interesting, the Editorial Board encourages innovative and interdisciplinary submissions.

$M W R$, now in its 136th year, is the longest-running, continuously published meteorological journal in the world. This new Editorial Board is honored to be a part of such a long and successful history. We hope you find the papers within these issues stimulating, educational, challenging, and useful in your work, whether it is for education, forecasting, research, or personal enjoyment.

Acknowledgments. Mary Golden and David Jorgensen provided comments to improve this editorial.

David M. Schultz

$M W R$ Chief Editor

University of Helsinki, and Finnish Meteorological Institute, Helsinki, Finland

\section{REFERENCES}

Batchelor, G. K., 1981: Preoccupations of a journal editor. J. Fluid Mech., 106, 1-25.

Errico, R. M., 2000: On the lack of accountability in meteorological research. Bull. Amer. Meteor. Soc., 81, 1333-1337.

Jorgensen, D. P., R. M. Rauber, K. F. Heideman, M. E. Fernau, M. A. Friedman, and A. L. Schein, 2007: The evolving publication process of the AMS. Bull. Amer. Meteor. Soc., 88, 1122-1134.

Keyser, D., and M. A. Shapiro, 1986: A review of the structure and dynamics of upper-level frontal zones. Mon. Wea. Rev., 114, 452-499.

Schubert, W. H., 1999: Editorial. Mon. Wea. Rev., 127, 3.

Schultz, D. M., and P. N. Schumacher, 1999: The use and misuse of conditional symmetric instability. Mon. Wea. Rev., 127, 2709-2732; Corrigendum, 128, 1573. 